\title{
Migrantes en situación de indigencia
}

\author{
Yadira Aguirre López, Rubith Anaya Coronado, \\ Ana Alicia Bejarano Villarreal y Luz del Carmen Gómez Verduzco*
}

\section{Introducción}

Datos de la Organización Internacional para las Migraciones $(\mathrm{OIM})^{2}$ estiman 214 millones de migrantes internacionales a nivel mundial, de los cuales el $49 \%$ son mujeres.

El fenómeno de la migración, interna como externa, es algo que ha estado presente por muchos años; cada persona puede observar desde los distintos puntos de su ciudad el flujo de las personas que transitan, con el fin de llegar a su lugar de destino (Estados Unidos). Las cifras han aumentado considerablemente, en 2011 el Instituto Nacional de Migración registró 9160 eventos de mujeres y niñas alojadas en estaciones migratorias, mientras que en 2012 este número ascendió a 11 958, lo que representa un incremento aproximado del $30 \%$.

Al aumentar el flujo de personas migrantes también aumentan los riesgos en el tránsito de ciudad a ciudad. Años atrás el hombre del hogar era el que migraba para darle una mejor calidad de vida a su familia, pero como ya se mencionó anteriormente, la mujer también comienza a migrar. Si el hombre sufría circunstancias difíciles como el robo, secuestro, violación, extorsión, daños en la salud debido a las altas y bajas temperaturas, accidentes por la forma tan peligrosa en que se trasladan, las mujeres son aún más vulnerables a sufrir todas las circunstancias mencionadas anteriormente.

Intentar comprender la complejidad de la conducta humana es todo un reto, sobre todo cuando pasamos a revisar las actitudes y comportamientos que tenemos

\footnotetext{
* Estudiantes de la materia Desarrollo Social y Políticas del Bienestar II, VI semestre de la Licenciatura en Trabajo Social, en el Departamento de Trabajo Social de la Universidad de Sonora: aguirreyari@gmail.com; anayacoronado@hotmail.com; aliicia.96@hotmail.com; anitabv@gmail. com; luzgomez2810@gmail.com

2 OIM. (2014). Hechos y cifras. Recuperado de http://oim.org.mx/ hechos-y-cifras-2
}

frente a aquello que es diferente o consideramos como amenaza. No podemos hablar de las desigualdades que se generan en la dinámica de la migración, sin antes entender que la individualidad de cada ser y su rol como miembro de una sociedad son determinantes en la construcción de la convivencia social; ya no solo se habla de la persona migrante, sino también de la relación que existe entre la migración y la indigencia, ya que muchos de los que migran se quedan detenidos o son deportados, y al no contar con documentos de identificación o por haber sufrido algún daño en la salud, causado durante el tránsito, se quedan en ciudades distintas a las de su lugar de origen y no logran conseguir un empleo que les dé los recursos económicos para sobrevivir en un lugar fijo.

En la mayoría de los casos no se cuenta con ningún familiar, las personas que se convierten en su familia son las mismas que se encuentran en su camino o en albergues donde les brindan un techo temporal. Al estar en medio de estas circunstancias la persona se convierte en indigente, ya que no cuenta con los recursos mínimos (techo, alimentación, vestimenta, servicio médico, etc.) para sobrevivir.

Es esencial, lograr la sensibilización de los individuos que rodean a las personas migrantes indigentes; pues estas no solo tienen que soportar sus circunstancias difíciles en las que migran, sino también el rechazo e indiferencia de las personas que se encuentran en su tránsito. Es indispensable poseer mejores conocimientos y capacidades en diferentes esferas normativas para asegurar la protección de los migrantes en situación de indigencia, facilitar la migración legal, promover la integración de los migrantes, y a su vez, lograr una mayor vinculación entre la migración y el desarrollo.

Existe en México la Ley de Migración, pero esta solo garantiza derechos independientemente de la situación migratoria del extranjero (salud, educación, acceso a la justicia) a las personas que cuentan con toda la documentación necesaria para hacer valer los derechos mencionados anteriormente. 


\section{Una realidad poco conocida}

Cada vez más migrantes pasan por el estado de Sonora, convirtiéndose en una de las fronteras más transitadas del país. Se considera que, a pesar de que hay programas e instituciones que apoyan al migrante, aún hay mucho trabajo que hacer, puesto que Sonora representa el primer lugar en migrantes repatriados de Estados Unidos de América (EUA) con el $37.1 \%$. Aunque se afirma que se hace de forma segura, la hermana María Ignacia Robles ${ }^{3}$, quien presta servicio en el comedor del migrante en la frontera de Nogales, comentó que a los migrantes les roban y los extorsionan; además, los que se suben al tren son golpeados, y que los siguen tratando muy mal. También expresó que actualmente se vive un fuerte flujo migratorio, principalmente de deportados.

Con relación al índice de llegada al comedor, ella comenta: "Están llegando 60, 70, 80; hubo un día que llegaron 120 y la mayor parte de migrantes, es porque están siendo deportados de Estados Unidos, familias que ya vivían allá muchos años". Tristemente con este acontecimiento muchas familias acaban divididas y desintegradas, quedándose estancados, sin papeles y sin los recursos necesarios para regresar a su lugar de origen.
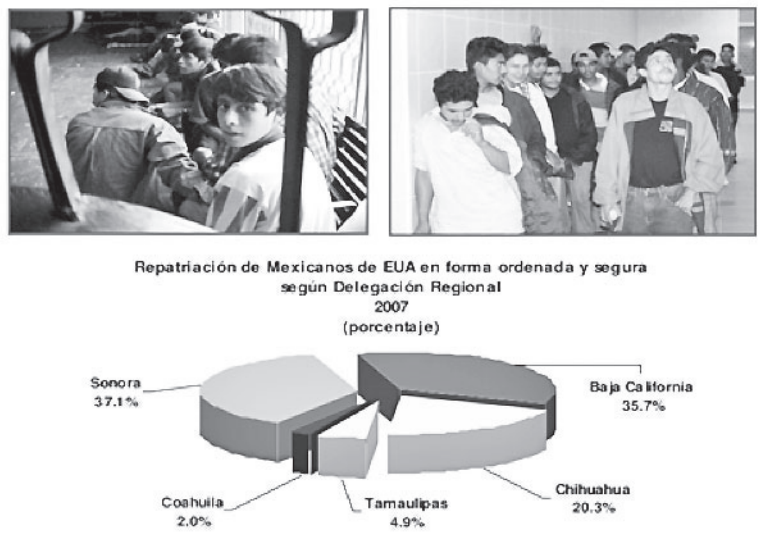

Fuente: Instituto Nacional de Migración

Se quiera o no, el ciudadano es parte y testigo de este fenómeno; lamentablemente, la mayoría prefiere ignorar y mantenerse al margen de la tremenda situación en la que el migrante se encuentra. ¿Qué se está haciendo por ellos? Sabemos que hay grupos de ayuda que les brinda comida un día o dos, y a veces hasta un techo donde dormir, pero ¿después?; estas personas en su camino tienen que enfrentar injusticias y abusos. Las autoridades que tienen la obligación de atender esta problemática son pasivas y poco sensibles.

Lo que se trata de resaltar es la situación del migrante; es importante aclarar que el fenómeno de la migración

\footnotetext{
${ }^{3}$ Fuente: Ruiz Rubén, A. (31 de enero de 2016). Llegan más deportados a comedor del Migrante. El Imparcial.

${ }^{4}$ Anuario de Migración y Remesas. (2014). BBVA Bancomer. Recuperado de https://www.fundacionbbvabancomer.org/ imagenes/Docs/AnuarioPres_2014May.pdf
}

no es el problema, lo es la calidad en la que estos migran y los grandes peligros a los que se exponen. Lejos de ser una dificultad para la sociedad, la migración contribuye al incremento socioeconómico del país, si nos ponemos a pensar en la cantidad de remesas que se reciben gracias a ella.

Según estadísticas ${ }^{4}$, en el 2013 Estados Unidos fue el país con mayor porcentaje de salida de remesas con un estimado de 128.0 miles de millones de dólares y México fue el cuarto receptor de remesas a nivel mundial con un estimado de 22 mil millones de dólares, solo superado por India (71 mmd), China $(60 \mathrm{mmd})$ y Filipinas $(26 \mathrm{mmd})$. A nivel Estado, ocupan el segundo lugar en índice de ingresos. No se puede negar que también causa muchos efectos positivos en la política fiscal y monetaria de los países de destino.

Nuestro primer contacto con las personas migrantes en situación de indigencia lo tuvimos en el Comedor y dispensario San Luis Gonzaga ubicado en el ejido La Victoria. En dicho lugar realizamos 25 encuestas a la población que allí llega a recibir los alimentos, pretendiendo conocer las condiciones de la migración, los problemas a los que se enfrentaron, las situaciones que se dieron en el camino desde el lugar de origen hasta este momento, entre otras cosas; y por supuesto también, considerar las necesidades por las cuales están enfrentándose en la actualidad.

Se pudo constatar, por lo menos a los que se entrevistaron, que vienen con una gran necesidad de tener un trato digno, un trabajo que solvente sus necesidades básicas y un techo seguro.

Esto lo expresaron tanto los que venían deportados, como los que apenas se iban a lanzar a la frontera. Se ve que tienen claro a lo que van, ya que dejan la seguridad en su lugar de origen, y están conscientes de que vale la pena pasar ciertas precariedades (enfrentarse con el clima, la migra, la delincuencia y con el crimen organizado, etc.), todo con el fin de cruzar al vecino país del norte. Comentaron que lo hacen porque no hay oportunidades ni apoyos para vivir dignamente en su tierra.

De las encuestas realizadas en el comedor y dispensario San Luis Gonzaga, un 56 \% dijo que salía de su lugar de origen por cuestiones económicas: "Nos estamos muriendo de hambre y no hay trabajo, y si acaso hay trabajo no nos pagan, y así es muy difícil sacar adelante a nuestras familias".
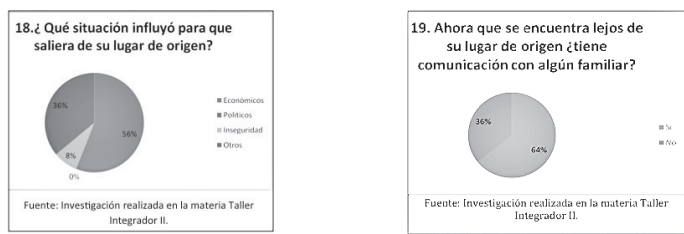

En el estudio exploratorio se encontró una diferencia entre la persona migrante y la persona indigente; la mayoría de los migrantes mantienen una comunicación con sus familiares en un $64 \%$, mientras que, en una colaboración con el DIF Hermosillo, al aplicar encuestas a personas en situación de calle, se encontró que un 80 \% de las personas indigentes no mantienen comunicación con sus familiares (no se cuenta con la cifra exacta). 


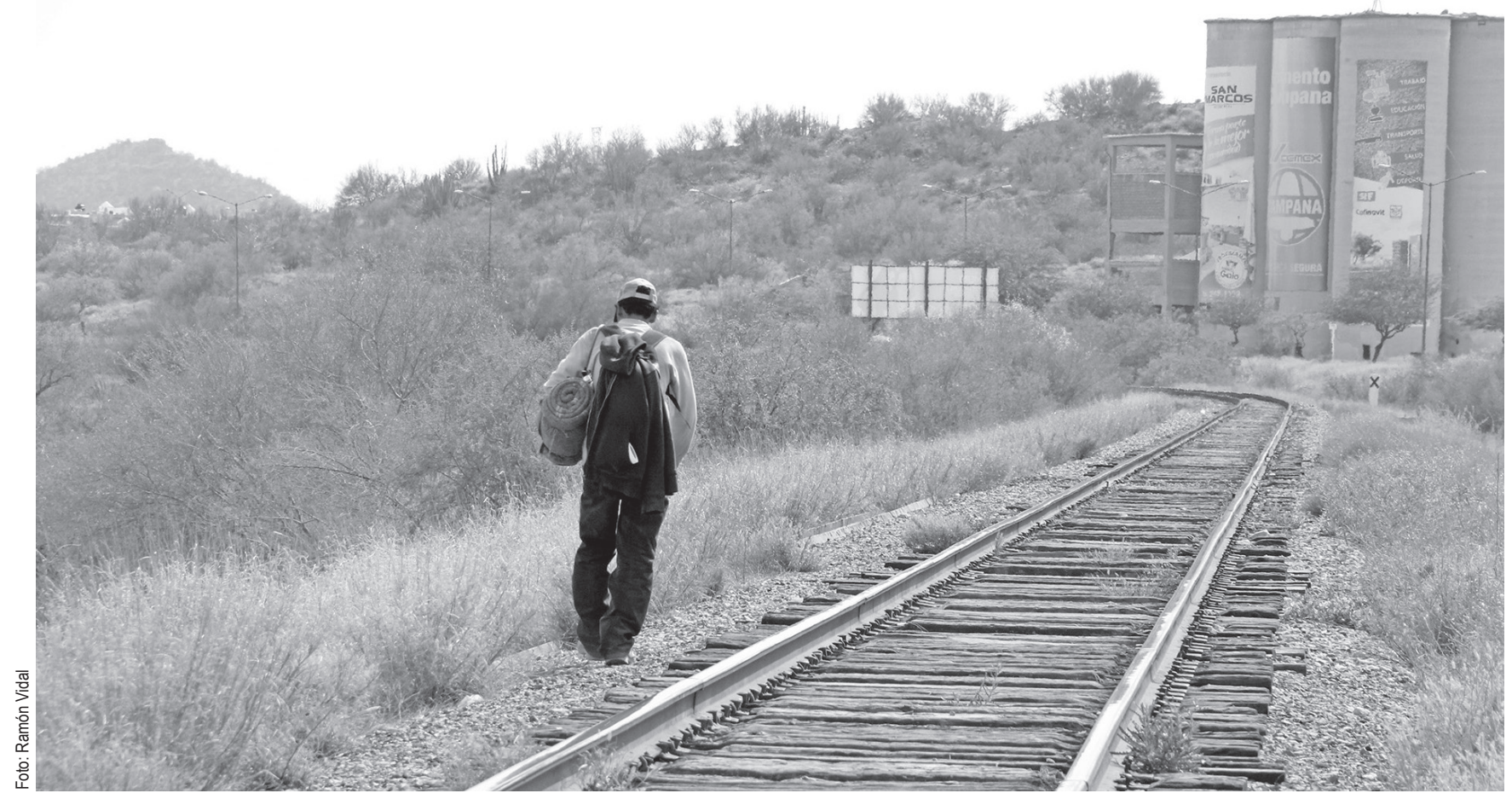

Con base en las encuestas aplicadas se encontró una convergencia en la situación vivida por el migrante y el indigente; el primero de ellos está porque las condiciones lo orillaron a vivir en vulnerabilidad; el segundo puede llegar a esta condición por varios factores, como salud mental, salud crónica (enfermedades contagiosas como la tuberculosis, herpes, etc.), por problemas familiares, haciendo de esta condición un modus vivendis.

\section{Conclusión}

El problema que se contempla no es la migración, la dificultad es que se frena ese tránsito por la pérdida de documentos de las personas migrantes, problemas de salud, el mal trato que reciben, principalmente por parte de las autoridades, hacen que las condiciones en las que transitan sean muy perjudiciales.

Es fundamental la sensibilización de los organismos gubernamentales, pero sobre todo reconocer la obligación de respetar los derechos humanos que tienen todas las personas, sin excluir a los migrantes indigentes, siendo imprescindible la ejecución de tales derechos.

Lamentablemente lo que se ha podido constatar es que no hay suficientes instituciones gubernamentales que den un servicio adecuado, las instituciones que lo hacen, aún sin contar con los recursos suficientes, son organizaciones religiosas y no gubernamentales, que se esfuerzan por que el tránsito de los migrantes sea libre y digno.

Es importante considerar que las personas migrantes indigentes son ciudadanos sujetos de derechos, sin embargo, en el proceso de seguimiento de esta población vulnerable, se

${ }^{5}$ modus vivendis: modo de vida que se adapta una persona. observa un gran desdén a sus derechos, en algunos como: de vivienda, salud, educación, identidad, derecho a un trabajo digno, libertad de tránsito y residencia.

A raíz de la realidad que está viviendo la población migrante indigente, surge la pregunta ¿qué se puede hacer? Por ello se le propone al gobierno municipal de Hermosillo Sonora, considerar la creación de un albergue para estas personas, pues lo prioritario es darles un techo en el que estén protegidos de los peligros de la calle y de las extremas condiciones climáticas que pueden afectar su estado de salud.

La atención en cuanto a salud es un derecho de todas las personas, por lo que se considera importante una atención médica de calidad a los migrantes indigentes, de manera que sea gratuita y completa; es decir, que se les dé un seguimiento en la atención de su estado de salud.

Se observa relevante la necesidad de que se creen talleres que capaciten para un trabajo a los migrantes deportados o que están de paso, y que por distinta situación se quedan como población flotante en condición de vulnerabilidad.

La pérdida de documentos de identificación de las personas migrantes es muy frecuente, ya que suelen perderlos en el camino o se los roban. Esta situación les reduce la oportunidad de emplearse, pues no cuentan con los papeles requeridos para ser contratados; es considerable que se creen políticas públicas que garanticen una atención más sistematizada en el trámite de documentos de identificación, de manera que sea ágil y sin ningún costo, evitando obstáculos en el proceso de solicitud de documentación de estas personas.

Es importante que en su paso por nuestra ciudad, se les demuestre solidaridad, se brinde orientación sobre los lugares donde pueden recibir ayuda, y ante todo se defienda sus derechos humanos. 


\section{DIRECTORIO}

\section{Hermosillo}

Comedor y dispensario San Luis Gonzaga, ONG

Grupos de atención: migrantes e indigentes

Dirección: calle Cayaco \# 12, ejido La Victoria, casi a orillas de las vías del ferrocarril

Servicios: se abre de lunes a viernes, todo el año. Se brinda solo una comida a mediodía a las 12:00. Se ofrece atención médica básica (algunos días va el doctor), ropa, calzado y cobijas, aseo personal, llamadas a familiares, orientación a migrantes centroamericanos, canalización al INM si ellos lo solicitan. Se reciben diariamente entre 120 personas, se han recibido hasta 225 personas.

Es atendido por: Pbro. Gilberto Lezama (fundador), Sra. Martha Silvia Molina, Sra. Carmelita y voluntarios de diferentes grupos parroquiales, de empresas, escuelas, instituciones, etc.

\section{Casa amiga IAP}

Grupos de atención: indigentes y migrantes

Dirección: calle Jesús García \# 100, colonia Centro, muy cerca del parque Madero

Servicios: hospedaje, desayuno y cena. Servicios de higiene, ropa y calzado. Se pide cuota de recuperación financiera, $\$ 10.00$ pesos diarios, está abierto permanentemente. Tiene capacidad máxima para 80 personas.

Es atendido por: Omar Peinado y es atendido diariamente por la Sra. Alicia, reciben el apoyo de iglesias, grupos, escuelas, empresas, etc.

\section{Obregón}

Casa del Pobre y Migrante

Grupos de atención: migrantes en general

Dirección: Constitución \# 145 entre Hidalgo y Narciso Mendoza, colonia Plan Oriente

Servicios: hospedaje y alimentación, servicios de higiene y atención médica básica, ropa y calzado.

Es atendido por: el Pbro. Alfonso Cota, sacerdote Diocesano

\section{Agua Prieta}

Centro de Atención al Migrante Exodus, A.C. (CAME)

Grupos de atención: migrantes en general, varones adultos y menores con familiares.

Dirección: calle 6ta. y avenida Anáhuac, S/N colonia Ferrocarril, C.P. 84200

Servicios: hospedaje, alimentación, ropa y calzado, asistencia médica básica, pláticas sobre derechos humanos y los riesgos de la migración, ayuda ocasional para la búsqueda de trabajo en la ciudad, gestión con autoridades consulares y locales.

Presta sus servicios desde hace 12 años a varones adultos y menores con familiares, su capacidad máxima es de 150 personas.
Es atendido por: el Pbro. Iván Bernal, actualmente no sabemos si hubo algún cambio.

\section{Centro de Recursos para Migrantes, módulo de atención (CRM)}

Grupos de atención: migrantes deportados en general.

Dirección: calle 1ra. avenida Panamericana S/N C.P. 26000

Servicios: es módulo de atención, otorga alimentación, ropa, calzado y medicamentos. Dan asesoría jurídica, gestión de transporte y llamadas telefónicas a sus familiares. Canaliza a migrantes según sus necesidades a los albergues y/o instituciones gubernamentales. Tiene una antigüedad de 8 años. Está abierto de lunes a domingo.

Es atendido por: Adalberto Ramos

Federación de Asociaciones Cristianas de Jóvenes de la República Mexicana, A. C. "Casas Ymca para Menores Migrantes"

Grupos de atención: niños migrantes entre 13 y 17 años de edad

Dirección: calle 7ma. entre avenida 22 y 23 \# 2205

Servicios: tiene capacidad para 30 niños y se les ofrece hospedaje y alimentación, servicios de higiene y aseo personal. Se les entrega ropa y calzado. El tiempo límite de estancia es de 4 días como promedio, se les brinda también el servicio de llamadas telefónicas para el contacto con sus familiares. Tiene 10 años de antigüedad. También tiene convenios con el Instituto Nacional de Migración (INM) y con la línea de autobuses Estrella Blanca para el retorno de los menores a sus lugares de origen.

\section{Altar \\ Centro Comunitario de Atención al Migrante y Necesitado (CCAMYN)}

Grupos de atención: migrantes en general, hombres y mujeres adultos

Dirección: avenida Gonzalo Senday \# 79, col. Buenos Aires

Servicios: hospedaje, solo pueden quedarse 4 días. Alimentación, solo desayuno 8 am y cena. Ofrecen ropa y calzado, asistencia médica básica, servicio de higiene y aseo personal, acceso a recibir y hacer llamadas telefónicas a sus familiares. El lugar tiene capacidad para 100 personas.

Es atendido por: la orden Escalabrinis, voluntarios hacen la comida y la sirven.

\section{Caborca}

\section{Comedor Padre González, ONG}

Pertenece a la Parroquia de Nuestra Señora de la Candelaria Grupos de atención: migrantes y personas en condición de calle

Dirección: calle 11 entre $\mathrm{G}$ y $\mathrm{H}$, frente a correos 
Servicios: comida solo a mediodía. Abierto de lunes a viernes. Se brinda ropa y calzado, asistencia médica básica. Capacidad para 80 personas aproximadamente. Se abre todo el año, desde sus inicios el año 2010.

Es atendido por: el sacerdote y señoras colaboradoras que preparan la comida.

\section{Benjamín Hill}

\section{Medalla Milagrosa}

Grupos de atención: migrantes en general

Dirección: calle Clemente entre Colosio y 2da., colonia Fondo Legal, al frente de la plaza.

Servicios: desayuno y hospedaje

Es atendido por: sacerdote

NOTA: no tenemos datos actualizados

\section{Nogales \\ Centro de Atención a Migrantes Deportados (CAMDEP) Grupos de atención: migrantes deportados \\ Dirección: Introspección de Reforma y periférico Luis Donaldo Colosio \# 55, col. del Rosario muy cerca del puente Mariposa, línea internacional, garita 2}

Servicios: Alimentación a personas deportadas y en tránsito, se les da ropa y calzado. Se les apoya con llamadas telefónicas, asistencia médica básica. En algunas ocasiones se les brinda apoyo económico para retornar a sus lugares de origen. Su capacidad es para 200 personas.

\section{Casa Nazareth}

Grupos de atención: solo reciben a mujeres con hijos

Dirección: edificio 4, departamento \# 502, col. Fovissste 2

Servicios: hospedaje y alimentación, el tiempo que pueden estar allí es una semana. Se les proporciona ropa y calzado. Pueden realizar llamadas telefónicas, retiro de dinero, apoyo para pasajes y atención médica básica. Tiene capacidad para recibir a 8 mujeres. Abrió sus puertas hace 5 años.

Es atendido por: religiosas

\section{Centro Comunitario Guadalupano de Nogales}

Grupos de atención: migrantes en general

Dirección: calle Latinos \#193, colonia Fundo Legal, zona centro

Servicios: se ofrece alimentación (una sola comida a las 2 pm). Se brinda ropa y calzado, asistencia médica básica e higiene, ayuda económica para retornar a sus lugares de origen.

Grupo de atención a migrantes varones adultos, con capacidad de 90 a 100 personas.

Es atendido por: Salvador Saucedo y Alma Cota, tiene aproximadamente 7 años sirviendo, abriendo de lunes a sábado de 13:00 a 15:00 horas.

\section{Albergue Cristiano La Roca, Exalbergue de la Esperanza}

Dirección: calle Independencia y Reforma \# 549, col. del Rosario

Servicios: hospedaje por 2 noches, se brinda alimentación y ropa. Atiende a hombres entre 16 y 40 años. Tiene capacidad de 50 a 60 personas.

Es atendido por: Sergio Arreola, contactos: Isabel Olivarría Ramírez y Giovanni Jiménez

\section{Albergue para migrantes San Juan Bosco, I. A.P.}

Grupos de atención: migrantes en general (familias, mujeres y hombres)

Dirección: Montaño \# 1063-A, col. Municipal

Servicios: hospedaje, alimentación (desayuno y cena). Ofrecen ropa y calzado, asistencia médica básica y apoyo económico para el retorno a su lugar de origen. Tiene 30 años prestando su servicio, dando hospedaje (asistencia) por 3 días máximo. Su capacidad es para 100 personas.

Es atendido por: Gilda Irene Esquer Félix.

\section{San Luis Rio Colorado}

\section{Casa del migrante "Divina Providencia"}

Grupos de atención: migrantes deportados

Dirección: avenida Zaragoza \# 912, entre 9 y 10

Servicios: hospedaje (no hay límite de permanencia).Se brinda desayuno y cena, asistencia médica básica, ropa y calzado, acceso a llamadas telefónicas. Tiene en función aproximadamente 20 años, atendiendo a Migrantes hombres y mujeres deportados. El lugar tiene capacidad para 54 personas.

Es atendido por: María Elena Ames de Salgado, contacto María Martha Vargas Ayala, es sostenido por patronato civil.

Un gran agradecimiento a la Maestra Maren Von Der Borch por el interés, apoyo y disponibilidad mostrado en este tema de investigación.

\section{Bibliografía}

OIM. (2014). Hechos y cifras. Recuperado de http:// oim.org.mx/hechos-y-cifras-2

Ruiz Rubén, A. (31 de enero de 2016). Llegan más deportados a comedor del Migrante. El Imparcial.

Anuario de Migración y Remesas. (2014). 26 de febrero de 2016, de BBVA Bancomer. Recuperado de https:// www.fundacionbbvabancomer.org/imagenes/Docs/ AnuarioPres_2014May.pdf 